Journal of Early Intervention, 1999

Vol. 22, No. 3, 217-229

Copyright 1999 by the Division of Early Childhood, Council for Exceptional Children

\title{
A Multi-site Evaluation of Parent to Parent Programs for Parents of Children With Disabilities
}

\section{GEORGE H.S. SINGER}

University of California at Santa Barbara

JANET MARQUIS

University of Kansas

\section{LAURIE K. POWERS}

Oregon Health Sciences University

LYNN BLANCHARD

University of North Carolina School of Medicine

NANCY DIVENERE

Parent to Parent of Vermont

BETSY SANTELLI

University of Kansas

JUDITH G. AINBINDER

University of Vermont

\section{MICHAEL SHARP}

University of North Carolina School of Medicine

This paper describes 2 approaches used to evaluate Parent to Parent mentoring programs in 5 states. Parents were assigned to either a treatment group or a waiting list comparison group. The treatment group participated in Parent to Parent for 2 months. Groups were compared on measures of coping, attitude, and progress on addressing problems. Analyses showed statistically significant positive gains for the parents in the treatment group. Changes on a measure of empowerment were not statistically significant. A qualitative study based on consumer satisfaction interviews with parents provided insight into what makes the Parent to Parent program work. The findings support the value of Parent to Parent selfhelp programs as one component of a family support system.

Parent to Parent programs for parents of children with disabilities are a grassroots self-help movement that has grown rapidly in the United States over the past decade (Santelli, Turnbull, Marquis, \& Lerner, 1995). These programs typically provide matches between trained supporting parents and parents who request assistance. The programs maintain a directory of parents who volunteer to assist other families. Generally, training is provided to 
the volunteer parents and they are matched to callers requesting help with challenges similar to those the volunteer has experienced. The program also performs an information and referral function by providing parents with the names of service providers, agencies, and in formal sources of support. Programs usually have a local or regional focus although several states have centralized statewide coordination. A recent survey of Parent to Parent Program participants reported that an estimated 20,000 parents are involved in Parent to Parent programs in 47 states (Santelli et al., 1995). This survey also reported that (a) the typical participant in Parent to Parent is a mother of a child with a disability, (b) $75 \%$ of the participants are Caucasian, (c) $78 \%$ are from two parent households, (d) and the majority are middle class. Santelli et al., also asked participants to describe the kind of assistance they most prefer from Parent to Parent: "Someone to listen and understand" was indicated by $66 \%$ of the respondents, followed by "dis ability information" (63\%); "care for my child" (58\%); and "ways to find services" $(54 \%)$. Based on this information it appears that Parent to Parent provides mothers with emotional support, practical information about caring for a child with a disability, and information about obtaining services.

Although Parent to Parent programs have enjoyed rapid growth and popularity, there is little published evidence regarding their effectiveness in helping parents of exceptional children. The nascent body of published literature is primarily descriptive, providing a useful profile of the membership and scope of activity of Parent to Parent programs. The one exception is a recent study by Silver, treys, Bauman, \& Stein (1996) who examined the impact of a parent mentoring program for parents of children with juvenile rheumatoid arthritis. Their randomized trial examined parent mentoring for its effect on measures of social support and mental health. No statistically significant differences associated with the treatment were found. Although they argued that there was a trend in their data toward a significant effect, there is no clear evidence for the efficacy of Parent to Parent programs. To further examine this question we designed a Participatory Action Research (Whyte, Greenwood, \& Lazes, 1989) evaluation study.

Participatory Action Research (PAR) has recently become the focus of research initiatives in disability fields (Heller, Pederson, \& Miller, 1995). PAR is characterized by collegial partnerships between researchers and the consumers and participants of research. Consumers and participants participate in the framing of questions, the design of the study, the selection of dependent variables, and the selection or development of dependent measures. They work collaboratively with the researchers in the conduct of the investigation and the analysis and interpretation of results. Finally, they share in the production of research reports and presentations. We established a research team made up of academic researchers and parent leaders of Parent to Parent programs.
Based upon extensive discussions with parents we developed a set of research questions. The process of developing the questions and hypotheses consisted of an extensive dialogue between the researchers and the parent leaders. We began with parent's accounts of why they believed Parent to Parent to be effective. Based upon numerous examples we developed some general categories for the kinds of as sistance that the programs appeared to provide. We also searched the literature on self-help movements to find a theoretical frame work that appeared to fit with the parents' descriptions of how and why Parent to Parent programs are helpful.

Self-help programs have a wide following in this country with membership estimated at 11 million (Katz, 1993). Many self-help programs are designed to help people with conditions that provide major challenges to their well-being and that entail divergence from expected life trajectories. Thoits (1986) proposed that self-help programs work via the perceived sameness of experience that members share. She argued that the social support offered by self-help groups serves as an extension of individual coping efforts. According to Thoit's theory, individuals' efforts to cope with challenging circumstances are enhanced and promoted through the modeling and practical advice offered by other members of self-help groups. Perceived sameness in the daily lived reality of exceptional life circumstances augments the credibility and salience of advice from a veteran. Because of sameness of experience, the help-seeking parents may more readily perceive that the supporting parents understand and respect their feelings without minimizing them. At the same time, the experienced helper who has come through similar difficulties with a positive attitude can model this outlook in a way that is believable.

In addition to the many stresses that all families experience, parents of children with disabilities face a variety of challenges that are uniquely linked to the disability, and the social construction and social consequences of its construction. For example, work in health psychology (Summers, Behr, \& Turnbull, 1989) has proposed that a child's disability provides a severe challenge to many parents and that many, if not most, respond effectively to this challenge through a process of cognitive adaptation. Taylor, Buunk, and Aspinwall (1990) found that cancer patients experienced the disease as a threat to their sense of meaning in life, their sense of self efficacy, and their sense of the benevolence and controllability of events, however, many patients adapted to the illness through mastery attempts that re-established a sense of meaning, enhanced self-esteem, and provided a sense of control. Taylor et al. also reported that social comparison played an important part in this process.

After extensive discussions with the parent members of our PAR team and a review of Thoit's theory of social support as an extension of coping and Summers et al, (1989) theory of cognitive adaptation to disability as a theoretical framework, we designed an experimental 
evaluation of Parent to Parent Programs in three regions of the United States. We hypothesized that Parent to Parent programs would be helpful to their members by assisting them in a process of adaptation involving both problem focused coping and cognitive and emotional adaptation. We expected positive changes in parents' estimates of (a) their ability to cope with a child's dis ability, (b) their sense of empowerment to effect change or obtain services for their children, and (c) their general acceptance of their family's life circumstances. Based upon Thoits' theory, we predicted that development of a sense of alliance with someone with a perceived high degree of similarity in parenting an exceptional child would function as a primary mechanism for facilitating the se changes. Furthermore, we expected that parents would make progress on addressing specific problems that led them to call a Parent to Parent program for help and that they would obtain more services as a consequence of participation in Parent to Parent.

\section{METHODS}

\section{Participants}

This study was conducted in five states: Kansas, New Hampshire, North Carolina, South Carolina, and Vermont. Parents of children with disabilities who responded to posters and flyers in physicians' offices, early intervention and NICU offices, and community centers in participating communities were participants in this study. The posters and flyer advertisements stated that we were looking for parents of children with disabilities to participate in a study of Parent to Parent self-help programs. Interested respondents telephoned a researcher who explained the study and gave parents an option of getting in touch with a Parent to Parent Program immediately rather than joining in the study. Those who wished to participate were mailed an informed consent form and an initial set of demographic and evaluation instruments. Selection criteria consisted of (a) being parents, foster parents, or grandparents of children with a disability or chronic health condition, (b) having access to a telephone, and (c) willing to wait for support from Parent to Parent for a period of up to 2 months if they were selected for the waiting list comparison group. Parents were excluded as participants if they currently were participating in a Parent to Parent program or were attending a support group for parents of children with disabilities. Over 200 individuals responded to our advertisements and expressed interest in participating in the study. After 28 respondents decided not to join the study because they wanted immediate help from Parent to Parent and another 4 dropped out to have their urgent needs addressed; we began the study with 172. After the post test, we eliminated 34 parents from the final data analyses because they did not complete a crucial questionnaire about the number of contacts they had with Parent to Parent during the study. (These parents did not not drop out of the study but they provided incomplete data on a crucial measure at post-test.) Thus 128 parents (72 in the control group, 56 in the treatment group) provided enough data to be included in final analyses. All parents completed most of the measures; however, some parents left one measure with only partial answers. When this occurred, participants were included only for analyses of the measures that were fully completed. Thus each ANCOVA used somewhat fewer participants than the total subject pool. This is a common problem in research involving multiple measures administered on more than one occasion and our analyses reflect common practice in regard to such studies. On some dependent measures there were fewer fully completed returns, thus analyses were done on a smaller number of participants when necessary. To determine if parents who did not fill out sufficient data at the time of the post-test were different than those who did, we compared their pre-test scores and found that they were not significantly different on the pre-test measures than the remaining participants. Consequently, there is no reason to believe that the differential numbers of participants with missing data biased the outcomes. To further safeguard against this possibility we used ANCOVA to control for any group differences at pre-testing.

Table 1 presents demographic data on parents and their children. Parents were asked to rate the severity of the child's disability as a general indicator of the child's status. Forty-five percent of the children were 5 years old and under and were being served by early intervention programs. Our sample consisted of mothers and only one father and slightly more than a third of the mothers were single parents. It addition, a substantial number of participants were from poor to lower middle incomes families.

Table 1.

Demographic Characteristics of Intervention and Waitinglist Comparison Groups

\begin{tabular}{lcc} 
& $\begin{array}{l}\text { Interven- } \\
\text { tion } \\
\text { Group } \\
n=56\end{array}$ & $\begin{array}{l}\text { Waiting } \\
\text { List } \\
\text { Group } \\
n=72\end{array}$ \\
\hline $\begin{array}{ll}\text { Child's age } \\
\text { Mean } \\
(S D)\end{array}$ & & \\
Disability & 6.9 & 7.7 \\
Mild & $(4.69)$ & $(7.8)$ \\
Moderate & $33.3 \%$ & $15.6 \%$ \\
Severe & $41.2 \%$ & $48.4 \%$ \\
Ethnicity & $25.5 \%$ & $36 . \%$ \\
African American & & \\
Anglo-Caucasian & $5.5 \%$ & $16.7 \%$ \\
Latino & $91 \%$ & $80.7 \%$ \\
Native American & $3.5 \%$ & $1.3 \%$ \\
& 0 & $1.3 \%$
\end{tabular}




\begin{tabular}{lrr} 
Parents Marital Status & & \\
Married & $69.6 \%$ & $61 \%$ \\
Single & $30.4 \%$ & $39 \%$ \\
Parents education & & \\
$\quad<$ High school & $3.6 \%$ & $4.2 \%$ \\
High school graduate & $25.5 \%$ & $28.2 \%$ \\
Some college & $38.2 \%$ & $33.8 \%$ \\
B.A. & $21.8 \%$ & $15.5 \%$ \\
Graduate degree & $10.9 \%$ & $18.3 \%$ \\
Family income & & \\
$\quad<15,000$ & $20.4 \%$ & $30 \%$ \\
$\$ 15,000-25,000$ & $18.5 \%$ & $20 \%$ \\
$\$ 25,000-\$ 35,000$ & $31.5 \%$ & $15.7 \%$ \\
$\quad \$ 35,000-\$ 50,000$ & $13.0 \%$ & $17.1 \%$ \\
$\quad \$ 50,000-\$ 75,000$ & $9.3 \%$ & $11.4 \%$ \\
$>\$ 75,000$ & $7.4 \%$ & $5.7 \%$ \\
\hline
\end{tabular}

Note. Age is reported in years. All parent participants were mothers except for one father in the intervention group.

\section{Design}

Quantitative study. The quantitative portion of our evaluation was based on a two groups (intervention and control) by two times (pretest and post-test) comparison design with random assignment. The control group was a waiting list control in which participants were provided with Parent to Parent support after post-testing. The major dependent variables for the experiment were: (a) perceived coping efficacy, (b) perceived empowerment, (c) attitudes of acceptance about one's circumstances and family, and (c) perceived progress in meeting the major need that parents expressed when they first called to participate in the study.

Qualitative study. To develop a better understanding of why Parent to Parent works for some parents and does not work for others, we conducted an additional qualitative study. We constructed a purposive sample to explore the questions that were the focus of our evaluation (Patton, 1990). Participants were 24 parents drawn from the pool of subjects who participated in Parent to Parent. We conducted telephone interviews with these parents using a standardized interview protocol. The interviewer was kept blind to the group status of the participating parent

\section{PROCEDURE}

\section{Quantitative Study}

A coin toss was used to assign parents to either an intervention group or a waiting list group. The intervention group members were given the telephone number of the closest Parent to Parent Program participating in our study. Parent coordinators from Parent to Parent programs received the calls and provided the typical intake interview procedures used by the program. Services offered by Parent to Parent were explained, questions about the problem that prompted the call were asked, and questions about their family and circumstances were asked to develop a profile for selecting an appropriate match. The help seeking parent was then given the name and phone number of a supporting parent. Supporting parents were asked to make four calls to the help-seeking parents over a 2-month period. Volunteer parent mentors received an average of 8 to 10 hours of group instruction on communication skills, information about services, and information about advocacy and support for families. Because some parents felt they needed help immediately and were not willing to risk being assigned to a waiting list group, our sample does not include parents with urgent needs for assistance. Although parents in crisis are commonly served in Parent to Parent programs, we could not ethically justify making them wait for help. As a condition of in formed consent, we assured parents that if they felt they could no longer wait for help from Parent to Parent, they could drop out of the study and be connected immediately to a program. Only 4 parents dropped out for this reason.

Pre and post test measures were mailed to parents over a 2-month period. Parents were mailed the pre test instruments prior to random assignment to a group; post tests were mailed 8 weeks after the initial contact with the parent or after initial contact with a researcher. Parents were paid $\$ 25$ for completing the assessments.

\section{Qualitative Study}

For the qualitative portion of the study we selected a subsample of 24 parents to represent each state. After the intervention was completed for both the waiting list and treatment group we constructed a list of parents who had been connected to a supporting parent through a Parent to Parent program. We divided the list into those who rated Parent to Parent as helpful and those who did not, and randomly assigned 12 participants to each of two groups. An interviewer, who was kept blind to group membership, conducted telephone interviews with each parent. Interviews lasted approximately 1 hour and were tape recorded for transcription. Verbatim transcripts were latter coded for identification of themes.

\section{Dependent Measures}

To test our measures we conducted a pilot study with 200 parents from a mid-Western state during the first year of our project. We used the pilot data to determine psychometric properties of the measures for this population and to compare them with published information about the psychometric properties of the instruments.

Cognitive adaptation. We used the Source of Strength and Family Closeness subscale of the Kansas Inventory of Parental Perceptions (KIPP; Behr, Murphy, \& Summers, 1992), a measure of positive attitudes about a child with disability in the family. The subscale consists of seven items about acceptance and perceptions of family adjustment. For example, two items about positive individual attitudes state, "I am more accepting of things" and " I am grateful for each day." Two items about family attitudes and adjustment state "My family has become closer (because of my child with a disability)" and "We are more in charge of ourselves as a family". This subscale was derived from a factor analysis of the KIPP based on a sample of 1,262 parents 
of children with disabilities. The factor loading scores for the seven items ranged from .69 to .48 . Coefficient alpha for the subscale was .86 . Evidence for convergent validity for this scale is the significant correlations with scores on the Family APGAR (Smilkstein, Ashworth, Clark, \& Montano, 1982), a measure of family well-being. Responses to items are structured on a 4point scale ranging from 1 (strongly disagree) to 4 (strongly agree). In an initial pilot study that we conducted with 200 families of children with disabilities in Kansas, the subscale also correlated in predicted ways with other measures of maternal stress (negative correlation) and social support (positive correlation) and it had adequate internal reliability and test-retest reliability with this specific population of parents who seek Parent to Parent help.

Empowerment. The Family Empowerment Scale (Koren, DeChillo, \& Friesen, 1992) was used to assess perceived changes in parent's sense of being empowered. It consists of three subscales that measure perceived empowerment in three domains: Family, Service System, and Community Political. Items are designed to measure attitudes, knowledge, and behavior. For example, an attitude item from the Family Empowerment subscale states, "I feel I can solve problems with my child when they happen." A knowledge item from the Service System subscale reads, "I know the steps to take when I am concerned that my child is receiving poor services." A behavior item from the Community Political subscale states, "I get in touch with my legislators when important bills or issues concerning children are pending." Answers are structured by a 5-point Likert scale ranging from 1 (not at all true) to 5 (very true). Based upon a sample of 440 members of parent groups in four regions of the U. S., internal consistency using the computation of Cronbach's alpha coefficients was found to range from .87 to .88 for the three subscales. A factor analysis yielded four factors that are consistent with the theoretical basis for the design of the instrument. Preliminary evidence for discriminative validity was also presented by the test authors (Koren et al.).

Coping efficacy. In order to measure parents perceptions of their efficacy at coping with problems related to their child and family, we administered the Parent Coping Efficacy Scale (PCES; Blanchard et al., 1996). A factor analysis of the PCES yielded two subscales: Coping with Child and Coping with Family. The items were developed by our panel of parent leaders with suggestions drawn from relevant literature provided by the researchers. The instrument consists of 24 items asking parents how they felt during the previous week. An example from the Coping with Child scale asks, "Over the last week, how capable have you felt dealing with your child's day-care or childcare needs?" An item from the Family scale asks, "Over the last week how capable have you felt about maintaining a fulfilling family life?" Respondents answer on a 5-point Likert scale ranging from 1 (not capable) to 5 (very capable). Internal consistency coefficients were level and to guard against Type I error. Thus, to be calculated (Cronbach, 1951) with alpha $=.89$ for the family subscale and .88 for the child subscale. The testretest reliability is $r=.82$. The PCES total scores correlated in predicted ways with measures of stress, social support, and cognitive adaptation. The PECS was developed in conjunction with this study and a detailed analysis of it is available in Blanchard et al. (1996).

Progress on presenting problem. To measure if progress was made on the specific problem they wanted Parent to Parent to address, parents were asked to respond to two questions: (a) "What is the major specific need that is influencing you to seek Parent to Parent support?" and (b) "How much progress have you made in getting that need met?" Responses were on a 4 -point Likert scale ranging from 1 (none) to 4 (a lot).

Perceived helpfulness of Parent to Parent. In the posttest administration, we included a question asking, "Overall how helpful was Parent to Parent?" Responses were structured as a forced choice on a 4point Likert scale ranging from 1 (not helpful) to 4 (very helpful).

\section{Descriptive Measures}

Demographic information. A demographic questionnaire collected responses from parents about their age, number of children, marital status, location of residence, and population of their residential area. Additional information on family income, highest level of education obtained, gender, birth date of the child with disability, child's primary diagnosis, and length of time since diagnosis also was obtained.

Number of contacts. On the post test we asked parents in the intervention group to report on the number of contacts they had with their matched parent and we asked them to indicate if the contacts were in person or by telephone.

\section{Qualitative Interview}

The qualitative portion of the study relied on semistructured interviews beginning with a general questions such as "How would you describe your Parent to Parent experience?" Open ended questions were followed by specific probes if the predesignated topics were not addressed. Questions directly asked what was helpful and was not helpful. Also included were questions about the match with a supporting parent, sameness of experience, convenience, topics shared with the matched parent, sources of strain, and the content of helpful interactions.

\section{Data Analysis}

Quantitative analysis. Because we believed the four major dependent variables (cognitive adaptation, empowerment, progress on meeting need, and coping) were conceptually dis tinct, we conducted separate analyses for each measure. We used an analysis of covariance (ANCOVA) for each dependent variable by using the pre-test score for each dependent measure as a covariate for each posttest measure. We used the Bonferroni procedure to adjust the alpha statistically significant, each $\mathrm{F}$ test had to represent a 
probability level (alpha) equal to or less than .012. In addition to the assumptions for any analysis of variance, ANCOVA also assumes that covariates have a linear relationship with the dependent variable and that there is homogeneity of regression. The PCES coping measure failed to meet the homogeneity of regression assump tion so we followed recommended procedure and used the Potthoff extension of the Johnson Nieman procedure (Aiken \& West, 1991).

Qualitative analysis. We coded transcribed interviews using an interactive process in which we identified themes as they emerged from the reading of the transcripts according to the constant-comparative procedures described by Lincoln and Guba (1985). This approach relies upon an inductive strategy in which data is divided into categories that are, to the maximum extent possible, unconstrained by prior assumptions about what parts of the phenomena are most important. Initially, we classified statements into two broad categories of aspects of Parent to Parent that were helpful and not helpful and most of the questions centered on this central concern. In subsequent iterations we identified themes within these categories as patterns of similar responses emerged from a reading of all 24 interviews. Although we did not set out to test a theory in coding the material, most of the themes that emerged were congruent with ideas from the literature on selfhelp (Thoits, 1988) and social comparison (Taylor et al., 1990). Consequently, we labeled several major themes with concepts from this literature. For example, several parents described how they were able to attain a special understanding with other parents because of their commonality of experience. We then categorized these statements under a label "experiential commonality", an idea that is mentioned in much of the literature on self-help groups. Because of space limitations we have presented a full analysis of this data in another article (Ainbinder et. al. 1996), however we draw upon some of the data from this qualitative study to help explain the results of the larger quantitative study.

\section{RESULTS}

\section{Quantitative Results}

Adjusted post-test means, numbers of participants per group, and the ANCOVA results are presented in Table 2. A pattern of statis tically significant gains on three measures and nonsignificance on one measure can be seen. Parents who participated in Parent to Parent demonstrated a statistically significant gain on a measure of acceptance of family and disability (Source of Strength and Family Closeness subscale of the KIPP). The ANCOVA found statistically significant differences at post-test between the two groups when pretest scores were used as covariates, $\mathrm{F}(1,121)=8.974, \mathrm{p}=.003$. This finding suggests that participation in Parent to Parent has a significant impact on attitudes that are thought to be primary components of parental cognitive adaptation to disability (Summers et al., 1989).

Some parents in the intervention group made gains in their perceptions of coping efficacy as measured by the PCES. As mentioned previously, the homogeneity of regression assumption was not met for the coping measure thus the Pothoff extension of the JohnsonNeyman procedure, described by Aiken and West (1991) was used. This procedure uses a Scheffe approach for control of Type I error, which was set at the .012 level. Because we had a lower return rate on the PCES than other instruments, the analysis was conducted on data from 96 participants (waiting list group $\mathrm{N}=51$, treatment group $\mathrm{N}=45$ ). For these data, the analysis determined that the region of statistically significant

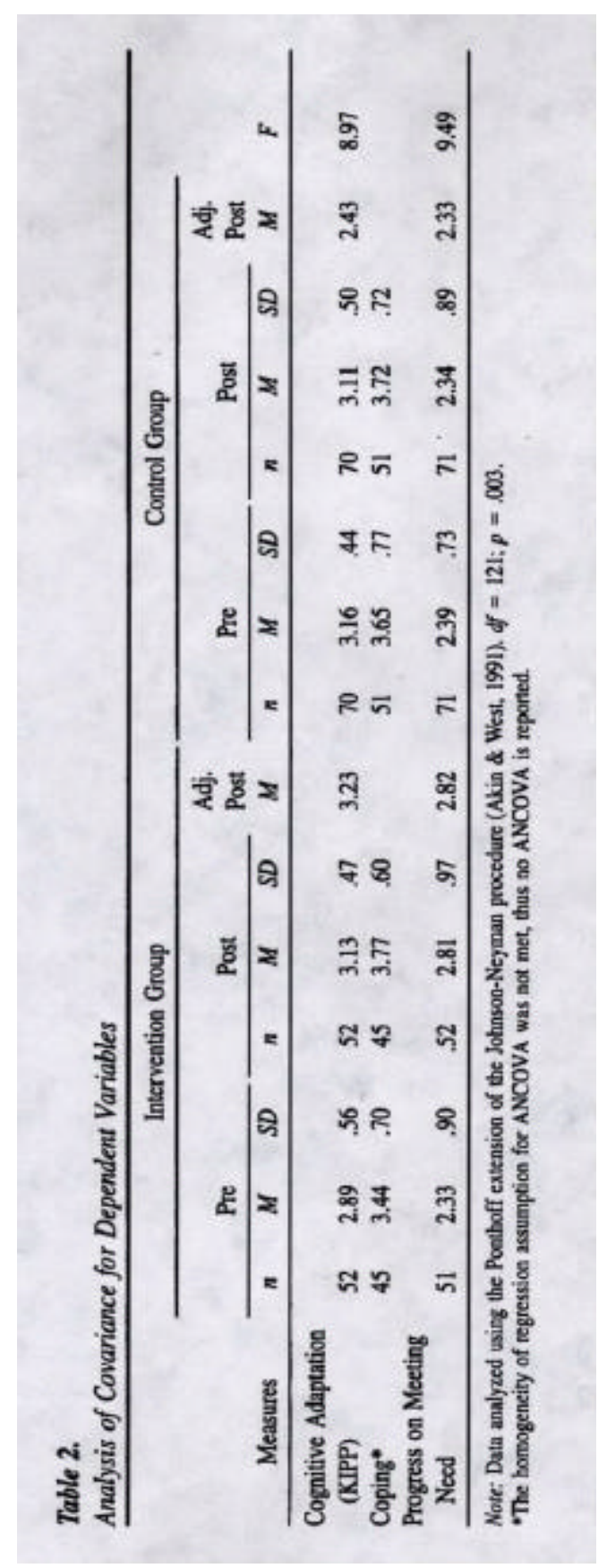


differences in the post-test score occurred for pretest scores at or below 3.07. This finding indicates that for parents who entered the study with levels of perceived coping skills below the 3.07 value, there were statistically significant differences on the post-test between the wait group and the parents enrolled in the Parent to Parent program. There were no statistically significant differences on the posttest between the two groups for those parents who scored above 3.07 on the pretest.

An ANCOVA, comparing post test scores for both groups (using pre-test scores as the covariate) on the measure of empowerment, did not detect statistically significant differences, $\mathrm{F}(1,122)=1.78, \mathrm{p}=.184$. This finding suggests that initial contacts in Parent to Parent do not change parents' perceptions of empowerment.

Parents' progress in meeting the primary need about which they were concerned when first contacting Parent to Parent was measured by asking one question, "How much progress have you made in meeting this need?" Results from the ANCOVA revealed statistically significant differences between the groups at post-test when pre-test scores were used as the covariate, $\mathrm{F}(1,112)=9.49, \mathrm{p}=$ .003 . This finding suggests that parents who participated in Parent to Parent made statistically significantly greater progress than members of the control group in getting help with the problem they first brought to Parent to Parent.

The number of contacts between supporting parents and parents who seek help is a basic descriptor of the core component of the Parent to Parent program. Our follow-up assessments revealed that a majority of parents, $61 \%$, had one or two contacts. Another $28 \%$ had three or four contacts, $8 \%$ had five or six and the remaining $3 \%$ had 10 or more contacts. On rating the helpfulness of Parent to Parent, $89 \%$ of the participants in the treatment group rated the program as helpful; $11 \%$ rated the program as not helpful.

\section{Qualitative Results}

The parent members of our PAR team suggested that Parent to Parent makes a difference in several ways. First, that by allowing a help-seeking parent to talk with a parent who has been through similar difficulties and now has a positive attitude about these difficulties, Parent to Parent facilitates an attitude shift for some parents. We selected a subscale of the KIPP to measure this attitude shift, and it revealed the projected changes in attitude when help-seeking parents were connected with supporting parents. Our qualitative interviews with parents suggest some of the mechanism by which these attitudes change. Thoits (1986) in a theoretical paper on social support and self-help groups suggested that perceived sameness is a key to this kind of unique salience of communication from someone who is living with a similar challenging life circumstances. It may be that this salience was even greater because some parents reported feeling isolated prior to their contact with Parent to Parent. For example, one parent told us,
Because I had been alone for 7 years and I was just kind of like, I just sat at home. I never really got out, and once I started with the support and its like oh, there's really people out here that understand me.

The discovery that "there's really people out here that understand me" was reported by a majority of interviewees who found Parent to Parent to be helpful. Parents who did not find Parent to Parent helpful either had practical problems that impeded contact, or they talked with another parent but did not find the contact salient. This minority of parents $(<11 \%)$ in the quantitative study reported there was something different about the supporting parent that seemed to get in the way of perceived sameness. Instead of sameness dominating their perceptions of the supporting parent, perceived difference took center stage. When difference prevailed the sense of being understood by another did not develop.

Those parents who did perceive sameness partly achieved this sense of sameness through a process of social comparison. Taylor et al., (1990) found that social comparison was at the heart of effective support group self-help for persons with cancer. Similarly, one mother in our study described social comparison in her own way:

It just helped me, you know, other parents are going through the same thing and just gave me ideas you know, like with what they experienced the same thing, you know, that I gothrough, or whatever, you know, just kind of compare.

Parents reported making comparisons about several different aspects of their lives. For example some found that it was helpful that their matched supporting parent had a child the same age as their child. One mother reported that it was helpful that she was the same age as her supporting parent because she felt she had more in common with members of her own generation. In the relatively small number of instances when the match did not go well, parents reported specific ways in which social comparison yielded contrasts. For example, one parent had a child who experienced cerebral palsy and who was nonvocal. She was matched with a parent of a child with cerebral palsy who spoke. She reported that this difference made the contact unhelpful.

Thoit's (1986) suggested that there is a fairly narrow band of similarity that operates in effective self-help. She discussed the way in which self-help members cannot be too different in their primary affect. Our interviews, however, suggest that affect is but one of several dimensions critical for successful matches. Some parents failed to achieve perceived sameness on dimensions such a child's speech problems, primary diagnosis, behavior problems, and differing opinions about particular professionals.

Perceived sameness and the process of social comparison allow people to exchange practical 
information about ways of coping with challenging life situations. Thoits (1986) described the way in which self-help group members possess a knowledge of the 24-houra-day reality of a condition that others simply do not possess. Our interviewees frequently mentioned this practical exchange:

It just-it's just nice to talk to somebody, you know, like if you don't know what to do and you want to find out what other parents are doing, how they handle certain things at home mainly.

Examples of the kind of practical information parents shared included suggestions about behavior management, toilet training, and what to expect at the next stage of child development. It is this exchange of practical information that may account for improvement in participants' coping efficacy. Perceived sameness makes information more credible. Highly believable information may account for the improvement in participants' coping efficacy. Many parents in our sample experienced gains in their perceived ability to cope with child and family associated with Parent to Parent involvement. Also, the practical exchange that is facilitated by perceived sameness and social comparison appeared to help parents meet the primary need that brought them to initially contact Parent to Parent.

\section{DISCUSSION}

Parent to Parent is a unique form of self-help for parents of children with disabilities. It has grown dramatically since the first program began in the early 1980 's with active programs currently in most of the U. S. and nascent programs emerging in Western and Eastern Europe. While these programs have evident appeal, reaching as many as 20,000 parents in the U.S., the only published efficacy study prior to this report did not find statistically significant effects. Unlike Ireys et al. (1996) we did find statistically significant improvements in parental self-reports when parents participated in a Parent to Parent program. Our findings thus provide the first evidence for efficacy of these programs. They suggest that parents who use Parent to Parent for non-emergency help benefit from contacts with other parents by (a) feeling better able to cope with their child and family situation, (b) feeling better able to view their family and personal circumstances in a more positive light, and (c) helping other parents make progress on goals that are important to them. Brief involvement with Parent to Parent did not help parents in feeling more empowered. This finding ran contrary to the reports of Parent to Parent leaders who had many accounts of members who became more assertive and effective in influencing conditions surrounding their children.
Until recently Parent to Parent programs have largely represented a movement of middle and upper middle class, Anglo-American mothers (Santelli, et al., 1995). In the past few years, however, many of these organizations have begun to expand their membership to include lower income parents and parents from ethnic minority groups. In addition, parents from ethnic minority groups have begun to form their own self-help organizations. In our sample $25 \%$ of the total sample had incomes below $\$ 15,000$ and $18 \%$ had incomes between $\$ 15,000$ and $\$ 25,000$. In these two income groups combined, 55\% rated Parent to Parent as helpful. Also, $11 \%$ of our sample were African-American parents. Thus, our results suggest that Parent to Parent is likely to also be useful to parents with low incomes.

The qualitative component of our study helps reveal why Parent to Parent programs are helpful or are not helpful. These findings may be particularly useful in assisting professionals to understand some of the differences between professional help and self help. Our findings were consistent with theory (Summers et al., 1989; Taylor et al., 1990; Thoits, 1986) in that similarity of lived experience and social comparison were reported as important aspects of the Parent to Parent experience. The first of these, a special kind of intersubjectivity based upon commonality of experience, is a unique contribution of Parent to Parent self-help. Although professionals can, and do, offer many important services, their language, viewpoint, and day to day experience is simply very different from that of family members. Professionals can offer accounts of other families they have known, but social comparison is likely to be more intensive when the comparison takes place through personal contact with others. In our view, these differences do not mean that self-help should replace professional help, although in respect to some kinds of assistance, this may be so. As part of our study we gathered information on who provides personal support to parents. The most commonly used sources of personal support (informational and emo tional support) were other family members, friends, and early intervention and school personnel. Thus professionals were viewed by a majority of these parents as important sources of support. Professionals, however, might benefit from understanding that they do not know the 24-hour reality of parenting a child with a disability. Supporting parents, on the other hand, do understand this reality and can understand a level of practical detail and subjective experience that is not as available to the professional no matter how well trained or experienced.

There are several explanations for why our results differ from those of Ireys and his colleagues (1996). First, we chose different dependent measures perhaps because our PAR process allowed us to choose measures based upon parents' in-put. We conducted a pilot study prior to the one reported here in which we tried similar measures chosen by Ireys and his colleagues and found them to not be sensitive to the kinds of changes that occur in Parent to Parent.

Other differences between the two studies include the fact that we had a somewhat larger number of participants and we were working with a somewhat different population. Most of 
our parents described their children as developmentally delayed or disabled and very few indicated that their children were chronically ill. Interestingly, the program described in the Ireys et al., study lasted longer and was more intensive, involving more phone contacts and more face to face contacts between parents than did our study. The relationship between outcomes and the intensity and duration of this form of assistance needs to be studied further.

Our study has some limitations that need to be considered for future research. First, all of the dependent measures relied upon self report from parents. No third party or observational measures were used. It is possible that rating by partners and professionals would triangulate results or contradict them. A multiple perspective evaluation would help to reduce possible problems of response bias when all measures are self report. Second, the study evaluated Parent to Parent over a fairly short time interval. It is possible that there are more powerful effects when measured over a longer period of time. By design, our study did not include parents in crisis. This small but important group may be helped more or less than our sample, thus we may not have obtained a complete view of the impact of Parent to Parent. Finally, because of our reliance on the PAR model and the specific nature of our research questions, we developed a new measure, the coping instrument (PCES). Although we were able to develop some of the psychometric properties for this instrument, it does not carry the same confidence of predictive and content validity that adheres to measures used and tested repeatedly. Given that out study found different results than Treys et al., (1998) it is important to replicate these findings before it becomes possible to say that the efficacy of Parent to Parent is a settled question.

Despite these limitations, our study does allow us to draw some overall conclusions about the effectiveness of Parent to Parent as a source of self-help in our sample. Overall, our findings suggest that Parent to Parent can be a valuable source of assistance for many parents of children with disabilities. It offers a unique form of assistance that is not typically met by the formal service system. We believe that Parent to Parent should be considered by policy makers and funders as a component of an array of family supports for families of children with disability. Eighty-nine percent of parents in this study rated it as helpful. Furthermore, it was helpful for a majority of lower income parents as well as middle and upper-middle class parents. Parent to Parent is particularly helpful in assisting parents to make cognitive adaptations to dis ability in the family, in making progress on dealing with specific problems, and in helping parents to become more effective at coping with the demands of parenting a child with a disability while maintaining a desirable family life.

\section{REFERENCES}

Aiken, L. \& West, S.G. (1991) Multiple regression: Interpreting interactions. Newbury Park, CA: Sage Publishing.

Ainbinder, J., Blanchard, L., Singer, G. H. S., Sullivan,M.E\& the Consortium to Evaluate Parent to Parent (1998). A qualitative study of Parent to Parent support for parents of children with special needs. Journal of Pediatric Psychology, 23, 99-109.

Behr, S. K., Murphy, D. L., \& Summers, J. A. (1992) Kansas Inventory of Parental Perceptions: Measures of perceptions of parents who have children with special needs. Lawrence, Kansas: Beach Center on Families and Dis ability, The University of Kansas.

Blanchard, L., Powers, L., Ginsberg, C., Marquis, J. \& Singer, G.H.S. (1996). The Coping Efficacy Inventory: Measuring parents perceptions of coping with a child with a disability and family problems. Unpublished manuscript. University of North Carolina Medical School, Chapel Hill, NC.

Heller, T., Pederson, E., \& Miller, A. (1995). Guidelines from the consumer: Improving consumer involvement in research. Paper presented at NIDRR conference on participatory action research, April, 1995, Washington, D.C.

Katz, A.H. (1993). Self-help in America: A social movement perspective Twyane Publishers: New York.

Koren, P. E., DeChillo, N. \& Friesen, B. (1992). Measuring empowerment in families whose children have emotional disabilities: A brief questionnaire. Rehabilitation Psychology, 37(4), 305-321.

Patton, M. Q. (1990). Qualitative evaluation and research methods (2nd ed.). Newbury Park, CA: Sage Publications.

Santelli, B., Turnbull, A. P, Marquis, J., \& Lemer, E.(1995). Parent to Parent programs: A unique form of mutual support. Infants and Young Children, 8(2) 48-57.

Santelli, B., Turbull, A. P., Sergeant, J., Lemer, E., \& Marquis, J. (1996). Parent to Parent: Parent preferences for supports. Infants and Young Children. 9(1), 53-62.

Silver, E.J., Ireys, H. T, Bauman, L, J., \& Stein, R. E. K. (1996). Psychological outcomes of a support intervention in mothers of children with ongoing health conditions: The parent-to-parent network. Journal of Community Psychology, 25, 249-264.

Smilkstein, G., Ashworth, C., \& Montano, D., (1982). Validity and reliability of the Family APGAR as a test of family function. Journal of Family Practice, 15,303311.

Summers, J.A., Behr, A. \& Turnbull, A.P. (1989). Positive adaptation and coping strengths of families who have children with disabilities. In G.H.S. Singer \& L.K. Irvin (Eds.) Support for caregiving families: Enabling positive adaptation to disability. Baltimore: Paul $\mathrm{H}$. Brookes, pp. 27-40.

Taylor, S. E., Buunk, B. P, \& Aspinwall, L. G. (1990). Social comparison, stress, and coping. Personality and Social Psychology Bulletin, 12(1), 74-89. 
Thoits, P. A. (1986). Social support as coping as sistance. Journal of Consulting and Clinical Psychology, 54(4), 416-423.

Whyte, W.F, Greenwood, D.J. \& Lazes, P. (1989). Participatory action research: Through practice to science in social research. American Behavioral Scientist (32)5, pp. 513-551.

This study was funded with grant \# H 13363008394 from the US Dept. of Education, NIDRR to the Dartmouth Medical School. The views stated in this report do not necessarily reflect those of the funders. The Consortium to Evaluate Parent to Parent is a coalition of leaders and researchers from Parent to Parent of Vermont, the Upper Valley Support Group in New Hampshire, Family First of North Carolina, Family First of South Carolina, and Families United of Kansas.

Address correspondence to George $\boldsymbol{H}$. S. Singer; University of California at Santa Barbara; Dept. of Education; Santa Barbara, CA 93106-9490. E-mail: singer@ education.ucsb.edu. 